index ecomunicación | no 11(2) 2021 | Páginas 231-255

E-ISSN: 2174-1859 | ISSN: 2444-3239 | Depósito Legal: M-19965-2015

Recibido el 25_04_2021 | Aceptado el 31_05_2021 | Publicado el 15_07_2021

\title{
LA COMUNICACIÓN DIGITAL \\ DE MÉDICOS SIN FRONTERAS \\ EN ESPAÑA DURANTE LA CRISIS \\ DE LA COVID-19
}

DIGITAL MEDIA STRATEGIES EMPLOYED

BY MEDÉCINS SANS FRONTIÈRES IN SPAIN DURING THE COVID CRISIS

https://doi.org/10.33732/ixc/11/02Lacomu

\begin{abstract}
Paula Rubio-Pinilla
Universidad Pablo de Olavide

96.prubio@gmail.com

https://orcid.org/0000-0001-6013-9109

Jose Candón-Mena

Universidad de Sevilla

jcandon@us.es

http://orcid.org/0000-0003-1070-4987
\end{abstract}

Proyecto de I+D «Ciberactivismo, Ciudadanía Digital y Nuevos

Movimientos Urbanos» (CiberMov). Ministerio de Economía

y Competitividad. Fondos FEDER. (Ref: CSO2016-78386-P) 
Resumen: Este artículo analiza la comunicación digital de Médicos Sin Fronteras durante su intervención en España a causa de la emergencia provocada por la COVID-19. Mediante un análisis de contenido de los mensajes publicados en su página web, los correos enviados a sus socios y sus publicaciones en Facebook y Twitter, categorizamos las temáticas, objetivos, enfoques informativos o emocionales, el emisor o el formato de una muestra de 58 mensajes. De forma complementaria, consideramos la intensidad, la dirección positiva o negativa o los términos más frecuentemente utilizados. Concluimos señalando cómo MSF ha enfocado su comunicación durante la crisis en explicar al público su intervención en España como forma de reforzar su imagen y sus atributos como una entidad especializada en la atención sanitaria en situaciones de emergencia. La inédita intervención en España ha servido a MSF para rendir cuentas a sus públicos mostrando la forma en la que habitualmente actúa en otros países.

Palabras clave: ONGD; Médicos Sin Fronteras; COVID-19; publicidad social; marketing social.

Abstract: This article analyzes the digital communication of Médecins Sans Frontières (MSF) during its intervention in Spain due to the emergency caused by COVID-19. Using content analysis techniques, the text engages with a number of the messages posted on the MSF website, emails sent to partners and publications on Facebook and Twitter. The material (a total 58 messages) is categorized by subject, sender, format, and objective, as well as the presence of informative or emotional approaches. Complementarily, items such as intensity, positive or negative undertones and the terms most frequently used are also examined. Our conclusion points towards the use of digital communication with a view to reinforce MSF's public image as an entity specialized in health care in emergency situations. The unprecedented intervention in Spain during the COVID-19 crisis has also shown MSF to be accountable to its audiences, showing how the organization usually works in other countries.

Keywords: NGDO; Médecins Sans Frontières; COVID-19;

Social Advertising; Social Marketing. 


\section{Introducción}

En este artículo examinamos, mediante un análisis de contenido, la comunicación de Médicos Sin Fronteras durante su actuación en España por la crisis sanitaria de la COVID-19. En primer lugar, introducimos el contexto de la pandemia y presentamos a la entidad, describiendo su actuación durante la crisis y en particular el contexto y su política comunicativa. En el marco teórico abordamos algunos debates sobre la comunicación de las ONGD y sus efectos y señalamos algunas de las características de la comunicación digital de este tipo de entidades que nos guiarán para diseñar el sistema de categorización del análisis empírico. Posteriormente se explica la metodología de forma detallada y se presentan los principales resultados. Finalmente, en las conclusiones, inferimos del análisis los objetivos y la estrategia comunicativa que definen la política de comunicación digital que ha llevado a cabo MSF.

En diciembre de 2019 se identificó en China el primer caso de infección SARS-CoV-2 causante de la enfermedad COVID-19. El 11 de marzo de 2020 la Organización Mundial de la Salud (OMS) proclamó el estado de pandemia internacional debido a la elevada mortalidad y morbilidad del virus. En España se declaró el Estado de Alarma el 14 de marzo de 2020 y se extendió hasta el 21 de junio de 2020. El sistema sanitario español quedó al borde del colapso. Ante esta situación de emergencia, organizaciones como Médicos Sin Fronteras (MSF) o Médicos del Mundo, expertos en epidemias y en enfrentar situaciones críticas, decidieron colaborar con el sistema sanitario español. Algo inédito en este tipo de organizaciones de desarrollo (ONGD) que, en general, llevan a cabo su misión social en países empobrecidos, conflictos bélicos o zonas azotadas por catástrofes naturales. En este texto nos centramos en el estudio de caso de MSF y su actuación en España durante la primera etapa de la crisis sanitaria.

Médicos Sin Fronteras se define como «una organización de acción médico-humanitaria». Su origen se remonta a 1967 en la guerra de Biafra durante el genocidio de la minoría Ibo. Surgió entonces la colaboración entre un grupo de médicos y periodistas que entendían que atender a las víctimas no era suficiente y era preciso influir en la opinión pública a través de los medios de comunicación mediante el testimonio y la denuncia. Con esa visión, el 20 de diciembre de 1971 se fundó oficialmente en Francia Médecins Sans Frontières con una doble misión social: la acción médico-humanitaria y el testimonio. La importancia dada a la comunicación está por tanto en el origen de MSF y forma parte fundamental de su misión social.

En el contexto de la crisis de la COVID-19 en España, las principales líneas de intervención de la ONGD han sido el asesoramiento técnico y la formación del personal de las residencias de mayores. MSF también instaló unidades de 
hospitalización temporal en colaboración con las autoridades y el personal de salud de distintas comunidades autónomas y ha ofrecido asesoramiento personalizado para responsables de las Administraciones, profesionales de la salud o personas afectadas por la COVID-19.

Respecto al contexto comunicativo, la difusión de información falsa o fake news (Orso et al., 2020) contribuyó a propagar el pánico, creó confusión y generó serias divisiones sociales (Aleixandre, Castelló y Valderrama, 2020). Ante la incertidumbre, MSF declaró en la edición especial de su revista Especial COVID-19 Contrarreloj que:

El conocimiento científico que se está produciendo y su difusión según avanza la propia epidemia están haciendo que se cambien protocolos y mensajes de manera muy rápida, casi vertiginosa, y estos cambios, como decíamos, generan inseguridad e incertidumbre en la población general. [...] Mientras no contemos con nuevas evidencias, la incertidumbre permanecerá como una nueva normalidad que hay que aceptar y gestionar con pedagogía y comunicación transparente (De Bartolomé, Jiménez y Moretó, 2020: 17).

Durante la pandemia MSF ha hecho hincapié a través de su plan comunicacional en ocho claves de salud y ha desarrollado diversas iniciativas solidarias a través de sus redes sociales. El presente estudio se centra en analizar la política comunicativa de MSF durante su intervención en España para enfrentar la crisis provocada por la COVID-19, entre los meses de marzo y mayo de 2020.

El objetivo de la investigación es identificar cuáles han sido los fines y prioridades comunicativas de MSF durante su actuación en España, así como analizar la estrategia de comunicación digital llevada a cabo por la ONGD para alcanzarlos. Nuestra hipótesis de partida es que la comunicación de MSF en esta situación primaría, por una parte, la labor informativa y educativa sobre el virus y las medidas de prevención $\mathrm{y}$, por otra, la justificación de su inédita actuación en un país desarrollado como España, lo cual podría generar dudas e incluso recelos entre sus socios y donantes.

Con el análisis de contenido realizado pretendemos responder a las siguientes preguntas de investigación: ¿Cuáles han sido los objetivos prioritarios de los mensajes difundidos por MSF en sus canales digitales? ¿Qué temáticas, referentes, enfoques y formatos predominan en sus mensajes? ¿Resultan coherentes para alcanzar los fines propuestos?

\section{Marco teórico}

Las ONGD se especializan en tareas de cooperación al desarrollo en países empobrecidos. Estas actúan directamente en el terreno, mediante la realización 
de proyectos de desarrollo en los países empobrecidos, o de forma indirecta mediante iniciativas encaminadas a movilizar a la opinión pública o presionar a las administraciones del Norte. Sus principales ejes de acción son los proyectos de desarrollo, la movilización de la opinión pública y el apoyo económico (Balas, 2011: 51). El caso de la intervención de MSF en España es pues una excepción y también una novedad para su política comunicativa.

Respecto a la comunicación de las ONGD, existe un amplio debate ético y cultural sobre las repercusiones de sus estrategias comunicativas en las sociedades del Norte a la hora de plantear los problemas del Tercer Mundo (Benet y Nos Aldás, 2003). La necesaria adaptación de la publicidad de las ONGD a un mercado de carácter consumista amenaza con «desfigurar la naturaleza crítica, participativa, estructuralmente transformadora y solidaria de las propias ONGD» (Benet y Nos Aldás, 2003: 57). Las estrategias comunicativas y sus posibles efectos no solo repercuten en la eficacia a corto plazo para la captación de fondos, sino que también tienen efectos educativos y culturales a largo plazo. Al respecto, diversos autores señalan las limitaciones de la comunicación de las ONGD dado su carácter instrumental, mediático y ligada generalmente a la búsqueda de financiación (Balas, 2011: 197; Bernabé, 2001: 145), con escasa proyección educativa (Erro y Ventura, 2002). No obstante, la comunicación se considera una función estratégica para las ONGD (Ferguson, 2017), hasta el punto de que para algunos autores la comunicación es la razón de ser de este tipo de entidades (Vernis y Mendiluce, 1998).

Desde el punto de vista del marketing, se ha señalado la política comunicativa como la más necesaria para el logro de los fines sociales de las ONGD (Aldamiz, 2003). Kotler y Zaltman (1971) definen el marketing social como la aplicación del marketing a un tipo específico de problemas donde el objetivo es cambiar el comportamiento social para beneficiar a la audiencia y a la sociedad en general (Andreasen, 1994).

Respecto a la comunicación digital, diversos estudios han analizado cómo las ONGD pueden aprovechar el potencial de las redes digitales (Campbell y Lambright, 2019; Deschamps y McNutt, 2014; Lovejoy y Saxton, 2012). Se ha destacado cómo estas ofrecen a las organizaciones una oportunidad para movilizar la acción colectiva (Greenberg y Macaulay, 2009), fomentando la sensibilización y participación de los públicos (Arroyo y Martín, 2011: 46; Arroyo, Baladrón y Martín, 2013: 85) e involucrándolos de forma activa (García y Del Hoyo, 2013).

Las redes digitales favorecerían un tipo de comunicación «fluida, continua y próxima» (De Andrés, 2007: 69), generando un diálogo más horizontal entre las organizaciones y sus públicos (Soria, 2011) y posibilitando 
una comunicación más efectiva, transparente, participativa, plural e inclusiva (Montoliu, 2012: 11). Una comunicación que algunos autores ven como especialmente indicada para la «transmisión de valores» (Baraybar, 2009: 42) y que podría fomentar el compromiso ciudadano (Arroyo, Baladrón y Martín, 2013; Soria, 2015).

También se ha señalado su utilidad para mejorar la fidelidad de los socios y donantes (Hayes y Westrup, 2014) y aumentar la confianza del público (Esparcia, Kunsch y Haswani, 2017), por ejemplo, mejorando la transparencia (Arroyo y Calle, 2018).

Para las ONGD, el uso de «tecnologías digitales de bajo coste» facilita las tareas de «información, participación u organización en red» (Lema, Rodríguez y Barranquero, 2016: 92), permitiéndoles obtener una adecuada difusión mediante la transmisión directa de sus mensajes (Couldry, 2010; Herranz, 2010; Martín, 2007) y reduciendo su dependencia respecto a los medios tradicionales (Cárcar, 2015).

No obstante, también se ha limitado el efecto de las redes digitales a la movilización puntual, señalando el carácter meramente informativo de los mensajes difundidos por las ONGD y su «limitada capacidad para captar la atención de los públicos» (Arroyo y Baños, 2013: 351). Por supuesto, el mero uso de las redes digitales no sería efectivo sin un trabajo comunicativo riguroso (Uribe, Rialp y Llonch, 2013) o si la comunicación digital de las entidades carece de una auténtica interactividad (Soria, 2011) que facilite la participación ciudadana. La escasez de recursos y de profesionales contratados (Lema, Rodríguez y Barranquero, 2016: 97), del tiempo necesario para planificar y ejecutar una buena estrategia comunicativa (Tian et al., 2019) o la falta de apoyo directivo (Arroyo, Baladrón y Martín, 2013: 85) llevarían a que muchas organizaciones no estén aprovechando al máximo el potencial de la comunicación digital (Pope et al., 2009). Así, se ha señalado la carencia de una clara voluntad por parte de las ONGD para establecer una verdadera conversación o interacción con sus seguidores, limitando la comunicación digital a fines instrumentales como fomentar la colaboración, la captación de fondos, la compra de productos o el voluntariado (Moriano, 2019).

En cuanto a los objetivos de la comunicación para las ONGD, esta puede servir a diferentes fines como sensibilizar, difundir, concienciar, educar, denunciar, cambiar, promover o presionar, entre otros (Herranz, 2009). De forma similar se han destacado como fines prioritarios la sensibilización de la ciudadanía, la notoriedad de las propias entidades, la recaudación de fondos y la presión a las administraciones (Vidal, 2003). Para Montero (2003), la comunicación cumple las funciones de informar, relacionar a través de vínculos 
racionales o emocionales, recordar, modificar la forma de pensar o reafirmar las conductas. Una encuesta realizada a representantes de 75 ONGD con sede en Estados Unidos concluyó que las dos funciones comunicativas más importantes eran la promoción de la imagen de la organización y la recaudación de fondos (Seo, Kim y Yang, 2009).

Teniendo en cuenta estas aportaciones, en nuestro análisis de contenido usaremos a modo de síntesis la propuesta de Hildegart (2006) que distingue entre cuatro tipos de finalidades comunicativas en las ONGD: sensibilizar, captar socios o recaudar fondos, educar o concienciar a los usuarios y ejercer presión o advocacy.

En cuanto a las temáticas de la publicidad social, estas han sido enmarcadas de forma general respecto a un único tema universal con el que estarían relacionados todas las causas y proyectos sociales: la protección de los derechos humanos (Alvarado, 2003: 357). No obstante, podemos distinguir cuatro áreas temáticas principales: la salud y el bienestar público y social, la marginación y discriminación, la protección del entorno natural y urbano y la solidaridad internacional (Alvarado, 2003: 357-359). En relación a nuestro objeto de estudio, MSF como el resto de ONGD se dedica básicamente a la solidaridad internacional, pero también, dada su especialización médicohumanitaria, la promoción de la salud y el bienestar es otro eje temático fundamental. En nuestro caso de estudio, debido a la inédita acción de la ONGD en territorio español en el contexto de la crisis sanitaria, el tema de la salud desplaza a la solidaridad internacional.

Por otra parte, se han señalado como los principales referentes de la comunicación de las ONGD a los problemas sociales, las soluciones propuestas, los productos sociales en que estas soluciones se concretan y las propias entidades u organizaciones (Alvarado, 2003: 362-363). Respecto a este último, nuestro enfoque analiza cuáles son las personas o colectivos que personalizan a la entidad y actúan como emisor de los mensajes. Aunque todos ellos parten de la entidad, esta se presenta generalmente a través de sujetos como los trabajadores o el equipo directivo, buscando complicidad y una comunicación más íntima y personal.

Respecto al enfoque y el tono de los mensajes comunicativos de las ONGD, se ha debatido ampliamente sobre el carácter racional o emocional, denotativo o connotativo, que debiera caracterizar la comunicación de este tipo de entidades. Sobre ello, Montero (2003) ha señalado la complejidad de elaborar mensajes para causas sociales definiendo como «un arma de doble filo» el uso de mensajes que apelan a lo emocional, y que pueden resultar efectivos para lograr efectos a corto plazo, y el empleo de mensajes racionales que considera 
necesarios para lograr cambios a largo plazo. Aldamiz (2003) destaca la sensibilización y educación para el desarrollo a largo plazo y la captación de fondos en el corto plazo como objetivos asociados a distintos enfoques discursivos. Por su parte, Martínez (1998) destaca que el producto genérico de las ONGD, la solidaridad, es un sentimiento por lo que la utilización de discursos emocionales parece adecuado. No obstante, el autor apuesta por el uso de mensajes connotativos como medio para captar la atención del receptor, mientras que defiende la necesidad del discurso denotativo para que las ONGD cumplan algunos de sus principales objetivos como lograr donantes estables, implicar a largo plazo al voluntariado, conseguir adhesión a sus valores solidarios o reforzar la transparencia y el rendimiento de cuentas ante la sociedad y los donantes. Nos Aldás (2010) apuesta en general por la función educativa de la comunicación social y propone de hecho un cambio de enfoque desde el discurso persuasivo ligado a intereses privados (advertisement) que busca la eficacia a corto plazo, hacia la apuesta por el discurso publicitario ligado a los intereses colectivos (publicity), en general más racional y educativo y que vele por la «eficacia cultural» de la publicidad social a largo plazo.

Partiendo de algunos de los conceptos teóricos señalados, se ha diseñado un enfoque metodológico basado en series de categorías que resultan útiles para analizar el contenido de los mensajes de MSF durante su actuación en la crisis sanitaria española.

\section{Metodología}

\subsection{El análisis de contenido}

El principal instrumento metodológico utilizado en esta investigación ha sido el análisis temático del contenido manifiesto de los mensajes de MSF durante la pandemia. Según Andréu (2002), el análisis de contenido está formado por un conjunto de técnicas que pretenden explicar y sistematizar, siguiendo el método científico, es decir, de forma sistémica, objetiva, replicable y válida, el contenido de los mensajes comunicativos (textos, sonidos e imágenes) así como su expresión. El objetivo principal es efectuar deducciones lógicas y justificables relativas a la fuente, teniendo en cuenta su contexto. Este tipo de análisis de contenido categorial temático o análisis temático considera, siguiendo a Arbeláez y Onrubia, «la presencia de términos o conceptos con independencia de las relaciones surgidas entre ellos» (2014: 20). Usamos por tanto la técnica de la identificación y clasificación temática.

Nuestras categorías de análisis se han definido por un doble proceso deductivo e inductivo. De esta forma, se ha procedido con un enfoque deductivo buscando en el texto categorías previamente establecidas y construidas 
mediante referentes teóricos, para posteriormente revisar y enriquecer el sistema de categorías mediante el método inductivo, emergiendo de una primera lectura del contenido nuevas categorías no contempladas a priori (Arbeláez y Onrubia, 2014). En cuanto al contexto, este ejerce un papel fundamental en el proceso de análisis (Van Dijk, 2017), ya que para desarrollar y dar explicación a un discurso es imprescindible atender al marco de comprensión en el que ocurre. La situación de emergencia sanitaria descrita en apartados anteriores será por tanto relevante a la hora de establecer inferencias a partir de los resultados del estudio. A continuación, se detallan las técnicas metodológicas empleadas y los diferentes pasos y operaciones llevados a cabo para delimitar el objeto de análisis y determinar las reglas de codificación y el sistema de categorías, así como garantizar la fiabilidad del proceso de codificación y categorización.

\subsubsection{Delimitación del objeto de análisis}

Nuestro objeto de análisis es la comunicación llevada a cabo por MSF durante su actuación en España por la crisis de la COVID-19. Para su delimitación, las unidades de muestreo se han seleccionado en base a criterios de inclusión y exclusión relativos al ámbito geográfico y temporal, al formato y a la temática objeto de estudio.

En primer lugar, la muestra se ha delimitado en el espacio-tiempo según dos requisitos: estar dentro del periodo temporal comprendido entre el 14 de marzo y el 25 de mayo del año 2020, esto es, coincidiendo con la vigencia del primer Estado de Alarma, y ser informaciones publicadas oficialmente por Médicos Sin Fronteras España, dirigidas al público español y haciendo referencia a la situación sanitaria del país. En segundo lugar, se acotó la muestra según el formato, centrando el análisis en el contenido textual de los mensajes emitidos por la ONGD. Aunque ello no excluye que la composición del mensaje contenga materiales no textuales (imagen, vídeo, etc.), se han incluido solo aquellos con una presencia relevante del texto estableciendo un umbral de inclusión de más de tres líneas de contenido textual. Se excluyen por lo tanto aquellos mensajes cuyo contenido sea exclusivamente material audiovisual, como fotos o vídeos, así como las charlas o talleres online retransmitidos en directo por expertos de la organización. No obstante, su presencia será tenida en cuenta a la hora de realizar inferencias sobre la política comunicacional de MSF dada su relevancia en cuanto a la función educativa de la ONGD.

Siguiendo dichos criterios de delimitación, las unidades de muestreo consisten en los textos difundidos por la ONGD mediante algunos de sus principales canales comunicativos. Respecto a los medios incluidos en la muestra, se han seleccionado los siguientes: la página web, los correos 
electrónicos dirigidos a los socios y las redes sociales Twitter y Facebook. Dada la delimitación formal mencionada, se han excluido de la muestra otras redes sociales como Instagram y Youtube que priman el contenido gráfico y audiovisual. Respecto al criterio temático que delimita el análisis al sujeto de estudio, se han seleccionado las publicaciones que tratan exclusivamente sobre la COVID-19 y cualquiera de los aspectos relacionados con el virus, la enfermedad, la crisis sanitaria y sus consecuencias en cualquier ámbito. Por último, cabe aclarar que conforme al sujeto de estudio se han excluido también aquellos mensajes difundidos por MSF, pero cuya fuente es distinta a la ONGD, por ejemplo, los retuits o las publicaciones ajenas compartidas en Facebook.

Las unidades de registro son los propios textos seleccionados, mientras que para la cuantificación y ponderación y su asignación a categorías temáticas se recurrió al conteo de los caracteres que componen cada texto. Como unidades de contexto se contemplarán mensajes difundidos en otros formatos que no serán analizados, como por ejemplo las mencionadas charlas y talleres educativos en formato vídeo que, si bien no son objeto de análisis, deben ser tenidos en cuenta para valorar el peso de las tareas educativas entre las acciones comunicativas llevadas a cabo por la ONGD, o acciones en prensa con fines de presión política como el informe «Poco, tarde y mal. El inaceptable desamparo de los mayores en las residencias durante la COVID-19 en España», que obtuvo una amplia repercusión.

\subsubsection{El sistema de codificación}

El sistema de codificación de los datos atenderá a la frecuencia en la muestra de cada unidad de registro. Nuestro análisis se basa en la lectura textual como instrumento de recogida de información. Según cada categoría se considera el texto completo (por ejemplo, para determinar el emisor) o se procede al recuento de los caracteres de cada unidad. En función del número de caracteres que se identifican como pertenecientes a una categorización u otra, se ha calculado un porcentaje que refleja la presencia de elementos asignados a cada categoría.

\subsubsection{Determinación del sistema de categorías}

La categorización «es una operación de clasificación de elementos constitutivos de un conjunto por diferenciación, tras la agrupación por analogía, a partir de criterios previamente definidos» (Bardin, 2002: 90). El principal criterio de clasificación para la categorización es temático, incluyendo series de categorías nominales sobre la temática del mensaje, la finalidad del mismo, el emisor de la comunicación o el enfoque racional o emocional del mensaje. De forma complementaria, se incluye también una categorización sobre el formato de las unidades analizadas. 
En primer lugar, tras una lectura general de los textos de carácter exploratorio, se ha diseñado el inventario de series de categorías y las categorías concretas de cada una de ellas para, posteriormente, proceder a la clasificación de las unidades analizadas y su asignación a cada categoría. Esta asignación basada en categorías simples siguió los criterios de unicidad, exhaustividad, significación y replicabilidad. En cuanto a la exclusividad, esta se determina en función de los textos o caracteres designados de forma mutuamente excluyente a cada una de las categorías del análisis, mientras que los textos de cada unidad se atribuyen a cada categoría de forma ponderada en función de la cuantificación de los caracteres. A continuación, presentamos el sistema de codificación y categorización utilizado:

Temática: dentro de esta categoría se encuentran las secciones:

1. Actividad de Médicos Sin Fronteras en España: información relativa al ejercicio desarrollado por la organización para enfrentar la crisis provocada por la pandemia.

2. Denuncia de la coyuntura en España: información dirigida a evidenciar las irregularidades en la gestión y apelar al gobierno, comunidades autónomas o líderes europeos.

3. Consejos y herramientas para la ciudadanía: información dirigida a la sociedad civil para educar sobre el nuevo virus, el comportamiento a adoptar para enfrentarlo, así como herramientas psicológicas para superar la situación.

4. Proposiciones solidarias y/o recaudación de fondos: mensajes dirigidos al ocio y entretenimiento para sobrellevar la situación, así como información relativa a las campañas de recaudación de fondos.

Finalidad: siguiendo la clasificación de Hildegart (2006) sobre la finalidad explícita del contenido publicado, distinguimos entre los siguientes objetivos:

1. Sensibilizar.

2. Captar socios o recaudar fondos.

3. Educar o concienciar a los usuarios.

4. Ejercer presión o advocay.

Enfoque: en cuanto al enfoque o el tono de la comunicación diferenciamos entre:

1. Racional, con textos de carácter denotativo, informativo, argumentativo o descriptivo que apelan al entendimiento.

2. Emocional, con textos de carácter connotativo y apelaciones emotivas a los sentimientos o emociones del público. 
Emisor: teniendo en cuenta que el emisor institucional de toda la muestra analizada es MSF, identificamos al sujeto que actúa como emisor de la comunicación y personaliza el mensaje transmitiendo la información en nombre de la ONGD, diferenciando entre:

1. Equipo general de MSF.

2. Trabajador.

3. Voluntario.

4. Donante o socio.

Respecto al sistema de categorización por formato, la delimitación de las unidades de muestreo se centra en el contenido textual de los mensajes. No obstante, se incluyen las unidades en las que, junto a contenidos en otros formatos, tenga presencia el contenido textual con al menos tres líneas de texto. De esta forma se atiende a la composición de los mensajes clasificados en:

1. Texto.

2. Texto asociado a una imagen.

3. Texto asociado a un vídeo.

4. Texto asociado a un vínculo.

\subsubsection{Fiabilidad}

En cuanto a la fiabilidad del sistema de categorización y codificación, siguiendo las recomendaciones de Krippendorff (1990), una muestra de las unidades de registro ha sido asignada a las distintas categorías de forma independiente por los dos autores del texto. Así, en torno al 10\% de las unidades (6 publicaciones) escogidas al azar han sido codificadas independientemente por el segundo autor, obteniendo una alta fiabilidad expresada en función del acuerdo alcanzado por ambos codificadores. Las coincidencias sobre la muestra lograron un nivel de fiabilidad del 83,33\% en la codificación. Las discrepancias fueron solventadas en una segunda fase del proceso mediante el acuerdo entre ambos codificadores, clarificando criterios que sirvieron para revisar la codificación del total de las unidades analizadas.

\subsection{Otras aportaciones cualitativas del mensaje}

Aunque nos centramos en el análisis de contenido detallado, también han sido estimadas otras aportaciones cualitativas del mensaje: la presencia o ausencia de elementos en el texto; la frecuencia de aparición de determinados términos; la intensidad del mensaje medida en función del uso de determinados tiempos verbales, adverbios de modo o adjetivos calificativos; la dirección del mensaje - positiva o negativa-, o el carácter transversal de determinadas unidades pertenecientes a varias subcategorías simultáneamente. Este análisis cualitativo 
es solo aproximativo y complementario respecto al análisis de contenido que se presenta en este artículo. Sin embargo, dado el trabajo de lectura y clasificación realizado, se ha juzgado conveniente apuntar al menos algunas conclusiones preliminares sobre las que se podría profundizar en investigaciones futuras.

\subsection{Muestra}

Considerando los criterios de inclusión y exclusión detallados en la metodología, para cada uno de los canales de comunicación contemplados se han realizado distintas operaciones para la selección final de los materiales analizados. A continuación, se detallan dichas operaciones y el resultado final de la muestra seleccionada para cada medio.

En la página web oficial de MSF, la primera criba de información se ha realizado en la sección «Actualidad/Noticias» de la web, utilizando su propio buscador con los filtros de búsqueda por país, fecha y temática. De esta forma se han seleccionado los siguientes criterios: País: España; Fecha: 2020; Temática: Coronavirus. Tras obtener 21 publicaciones con estas características, se ha procedido a la segunda criba, excluyendo de la muestra aquellas publicaciones de 2020 que no se encuentran dentro del periodo temporal delimitado, así como aquellas unidades que contienen un formato meramente audiovisual. El resultado final es una muestra de 12 publicaciones.

Médicos Sin Fronteras España cuenta con casi medio millón de socios, según la memoria publicada en el año 2019 por la organización. Entre los canales de comunicación con sus socios hemos escogido el correo electrónico. Durante el periodo seleccionado los socios recibieron un total de 5 mensajes, de los que se ha excluido solo uno cuyo contenido se basaba en una compilación de anuncios sobre noticias variadas, pero sin un texto unificado que analizar. Por tanto, la muestra final cuenta con 4 correos electrónicos.

La comunidad de Facebook de MSF fue creada en julio del año 2018 y cuenta con más de tres millones de miembros. Para el análisis se han escogido las publicaciones del muro en la página de la organización comprendidas en el periodo temporal especificado, siendo estas 89 publicaciones en total. En una segunda criba se han excluido las publicaciones cuyo contenido no trata sobre la COVID-19 en España, quedando la muestra reducida a 55 publicaciones. Finalmente, se ha realizado una nueva selección basada en el formato por la cual se han excluido: las publicaciones que publicitan un contenido mediante un link que redirige al usuario a otra plataforma o medio; las publicaciones que contenían charlas online de MSF; aquellas cuyo formato principal es el vídeo; y las publicaciones cuyo contenido principal era una foto, galería o infografía cuando no iban acompañadas de más de tres líneas de texto. Como resultado se ha obtenido una muestra final de 20 publicaciones. 
El perfil oficial de MSF en España (@MSF_España) tiene más de 430 mil seguidores y actividad de forma continuada. En un primer momento se han seleccionado todos los tuits publicados por el perfil de MSF España en el periodo temporal analizado con el hashtag \#COVID19 con el que la ONGD etiquetaba los mensajes sobre esta temática. En una primera selección de tuits directos, es decir excluyendo retuits, respuestas en hilos o a otros perfiles, se han obtenido 323 unidades, de las cuales se han eliminado un total de 290 según los distintos criterios. Por su ámbito geográfico se han excluido 96 que aludían a la situación de otros países. Por criterios temáticos se han excluido 31 publicaciones que abordaban predominantemente otros temas. Finalmente, por su formato se han excluido 31 publicaciones cuyo principal objetivo era redirigir mediante un enlace a noticias publicadas en otros medios de comunicación o a otros perfiles en las redes digitales. Otras 12 publicaciones se han eliminado porque su contenido básico era publicitar charlas online en directo de los expertos de MSF. Finalmente 76 publicaciones han sido excluidas por predominar el formato vídeo o foto sin contener al menos tres líneas de texto. Dado el uso particular de esta red por parte de MSF, también se han excluido 54 publicaciones por estar repetidas y ser similares a otras publicadas con anterioridad o contener exclusivamente citas textuales de otros mensajes. Como resultado se ha obtenido una muestra final de 22 tuits.

Finalmente hemos definido una muestra de 58 mensajes en los cuatro medios seleccionados para nuestro análisis, como se detalla en la Tabla 1.

Tabla 1. Número de unidades de la muestra seleccionadas por tipo de medio y total

\begin{tabular}{|l|r|}
\hline Página web (noticias) & 12 \\
\hline $\begin{array}{l}\text { Comunicación interna } \\
\text { (correos electrónicos a los socios) }\end{array}$ & 4 \\
\hline Facebook (publicaciones en el muro) & 20 \\
\hline Twitter (tuits) & 22 \\
\hline Total & 58 \\
\hline
\end{tabular}

Fuente: elaboración propia. 


\section{Análisis y resultados}

\subsection{Publicaciones de la página web}

Los resultados del análisis de las noticias analizadas en la página web de MSF respecto al sistema de categorías temáticas comprenden 12 publicaciones de las cuales el $50 \%$ tratan la actividad desarrollada por la organización en España durante la pandemia de COVID-19, el 41,66\% de las publicaciones advierten sobre la situación y/o apelan a las autoridades y solo una, el 8,33\%, consiste en una proposición solidaria para recaudar fondos. Ninguna de las publicaciones de la muestra trata exclusivamente de aportar consejos o herramientas para la ciudadanía sobre cómo enfrentar el virus y sus consecuencias. En cuanto a su finalidad, categorizada de forma ponderada mediante el conteo de caracteres del texto, de las 12 publicaciones el 50,83\% del texto tiene la finalidad de informar al lector, el 35\% se trata de apelaciones a las autoridades, el 9,16\% persigue educar o sensibilizar y el $5 \%$ busca recaudar fondos o captar socios. Respecto al enfoque, el $84,41 \%$ de los mensajes tienen un carácter informativo o descriptivo, mientras que el 15,58\% tienen un enfoque emocional o apelativo con el que llaman a la movilización del lector. Respecto al emisor del mensaje, en el 63,91\% de las publicaciones el protagonista es el equipo global de MSF, mientras que en el $35,91 \%$ el emisor es un trabajador específico. Ninguna de las publicaciones de la web está firmada por voluntarios, donantes o socios de la entidad. El formato predominante es el texto acompañado de una imagen, una composición presente en el $87,5 \%$ de las publicaciones, mientras que en un $12,5 \%$ de las noticias de la web el texto se acompaña de un vídeo.

Sintetizando los resultados, en la página web oficial de MSF predomina la información sobre la actividad de la organización y el ejercicio de denuncia del contexto político y social. El carácter de los mensajes es mayoritariamente informativo/descriptivo, emitidos por el equipo global de MSF y haciendo uso de imágenes e infográficos para acompañar el texto.

Respecto al análisis cualitativo complementario, la intensidad de los mensajes es alta, debido al continuo uso de un gran número de adjetivos calificativos, adverbios de modo y determinados usos temporales. Algunos ejemplos de esto son expresiones como «enorme desafío», «dramática escasez», «muriendo solos» o «enormemente preocupados». En términos generales, la dirección del mensaje es negativa, lo que se muestra en un empleo frecuente de expresiones y términos como «obstaculizar la capacidad para salvar vidas» o «no debería suceder». Las palabras con mayor frecuencia de aparición en las publicaciones son «salud», «coronavirus», «médicos», «residencias» y «mayores». 


\subsection{Correos electrónicos enviados a los socios}

Los resultados obtenidos respecto a la temática de los 4 correos electrónicos analizados muestran el predominio de las proposiciones solidarias para el lector y/o recaudación de fondos a los que se dedican 3 de los 4 correos, el $75 \%$ de las unidades analizadas. El otro mensaje trata sobre la actividad desarrollada por la organización en España durante la pandemia de COVID19. La finalidad comunicativa de los correos es informar a los socios, objetivo presente en el 55\% del contenido analizado. Le siguen el objetivo de recaudar fondos o captar socios, presente en el $38,5 \%$ de los textos, y la finalidad de educar o sensibilizar con el 6,5\%, estando ausente en estos mensajes la apelación a las autoridades. El enfoque mayoritario en los textos, $63,74 \%$ de los caracteres, es informativo o descriptivo, mientras que el $36,25 \%$ restante es connotativo o emocional. El emisor predominante es de nuevo el equipo global de MSF que firma 3 de los 4 correos, el 75\%, estando el restante mensaje protagonizado por un trabajador específico de MSF. El formato de los correos internos se divide al $50 \%$ entre el texto acompañado de una imagen o de un vínculo.

En este canal abundan las proposiciones solidarias al lector para la recaudación de fondos y, en coherencia, también hay más equilibrio entre el tono racional y emocional, algo lógico en una comunicación dirigida a los socios. Los mensajes son también firmados por el equipo global de MSF y presentan mayoritariamente imágenes y vínculos junto al texto.

En cuanto a las características cualitativas de los correos, la intensidad de los mensajes es alta y con gran carga emocional, destacando su tono íntimo y cercano. Abundan los adjetivos y adverbios de modo, con el uso de expresiones tales como «sumando nuestros esfuerzos» o «todos somos necesarios». La dirección del mensaje es mayoritariamente positiva y las expresiones con mayor frecuencia de aparición son «apoyo», «sanitario», «iniciativa», «luchar» $\mathrm{y}$ «sistema de salud».

\subsection{Publicaciones en Facebook}

En la red social Facebook las temáticas predominantes son la actividad desarrollada por MSF en España durante la pandemia, presente en el 45\% de los posts, seguida de las proposiciones solidarias para el lector y/o recaudación de fondos en el $35 \%$ de las publicaciones, las apelaciones a las autoridades con un $15 \%$ de presencia y finalmente los consejos y herramientas para la ciudadanía sobre cómo enfrentar el virus, que se encuentran en el 5\% de los mensajes publicados en el muro. La principal finalidad comunicativa de estas publicaciones en Facebook es la de informar al lector, que alcanza el 50\% de las unidades analizadas. Le sigue la finalidad de captación de socios o recaudación 
de fondos con el 30\% de las publicaciones. El resto se reparte equitativamente con un $10 \%$ de mensajes que buscan educar o sensibilizar y otro tanto dirigido a apelar a las autoridades. El enfoque mayoritario vuelve a ser denotativo, con un $79 \%$ del contenido de las publicaciones de carácter informativo o descriptivo. El enfoque connotativo que apela a las emociones o sentimientos del lector está presente en el $21 \%$ del contenido de los mensajes. El equipo global de MSF vuelve a ser el principal protagonista como emisor de los mensajes publicados en Facebook, con un 92\% de los mismos. Solo en el 8\% restante el mensaje se transmite a través de un trabajador específico de MSF. En cuanto a la composición de las piezas, el $50 \%$ de las publicaciones acompañan al texto con una imagen, en el 35\% de los casos se añade un hipervínculo y en un $15 \%$ de los posts solo tiene presencia el texto.

En resumen, en Facebook prevalece la labor informativa sobre la actividad de MSF, pero también tienen una presencia importante las proposiciones solidarias o la denuncia pública. El carácter de los mensajes es informativo, emitidos casi siempre por el equipo global de MSF y con un formato básicamente textual, pero también acompañado de imágenes y vínculos para completar el texto.

Cualitativamente, vuelve a encontrarse una intensidad alta en el contenido de los mensajes con la profusión del empleo de adjetivos, adverbios y determinados usos temporales. Por ejemplo, «nuestra más sentida gratitud» o «extremadamente preocupados». Abunda el enfoque positivo y las palabras con mayor frecuencia de aparición en las publicaciones son «residencia», «hospital», «mayores»y «salud».

\subsection{Mensajes en Twitter}

En los tuits emitidos desde la cuenta oficial de MSF España, la principal temática presente es de nuevo la actividad desarrollada por la organización durante la crisis sanitaria en el país, a la que hacen referencia el 40,90\% de los mensajes en Twitter. La apelación a las autoridades españolas se encuentra en el 27,27\% de las publicaciones. Le siguen las proposiciones solidarias o llamadas para la recaudación de fondos con el 18,18\% y la difusión de consejos a la ciudadanía para afrontar la situación con el 13,63\% de los tuits publicados. Los objetivos o fines perseguidos por los mensajes en Twitter se reparten de forma bastante equilibrada entre el 31,81\% del contenido con fines informativos, el 25,45\% de caracteres que buscan educar o sensibilizar y el $24,54 \%$ cuyo fin es la presión a las autoridades. Un poco más rezagada encontramos la finalidad de recaudación de fondos o captación de socios presente en el 18,18\% de los tuits publicados. Los mensajes son mayoritariamente informativos o descriptivos, con un $81,81 \%$ del contenido de carácter denotativo, mientras que el $18,18 \%$ 
restante tiene un enfoque connotativo con apelaciones al receptor de carácter emocional. En cuanto el emisor de los mensajes, es el equipo global de MSF el firmante del $100 \%$ de los tuits analizados. El 43,18\% de los textos se acompañan de un enlace, el 34,09\% contienen material gráfico y el 22,72\% de los tuits incluyen material audiovisual, estando solo el 9,09\% compuesto exclusivamente por elementos textuales.

Por tanto, en Twitter predomina la información sobre la actividad desarrollada por la organización, pero también con bastante equilibro respecto a la presión política y los llamamientos a colaborar con la entidad. El carácter de los mensajes es casi siempre informativo o descriptivo. Son emitidos por el equipo global de MSF en su totalidad y hacen un uso frecuente de imágenes, vídeos o enlaces para acompañar el texto.

Otras aportaciones cualitativas al análisis señalan una intensidad más moderada en esta red social, manteniendo el tono mayoritariamente positivo del resto de medios analizados. Los tuits contienen expresiones como «estamos preparados», «trabajamos apoyando», «nuestro deber», etc. La frecuencia de aparición de términos es de carácter bajo debido a los requisitos de formato de la plataforma social, aunque las palabras que más aparecen en el conjunto de publicaciones son «COVID-19», «España», «Epidemia», «coronavirus» $\mathrm{y}$ «salud».

\subsection{Resultados globales}

A continuación, se presenta una serie de gráficos con la compilación de los resultados globales en los cuatro canales comunicativos de MSF analizados, a partir de la muestra global de 58 unidades de registro que componen el estudio.

Figura 1. Resultados globales sobre la temática de los mensajes

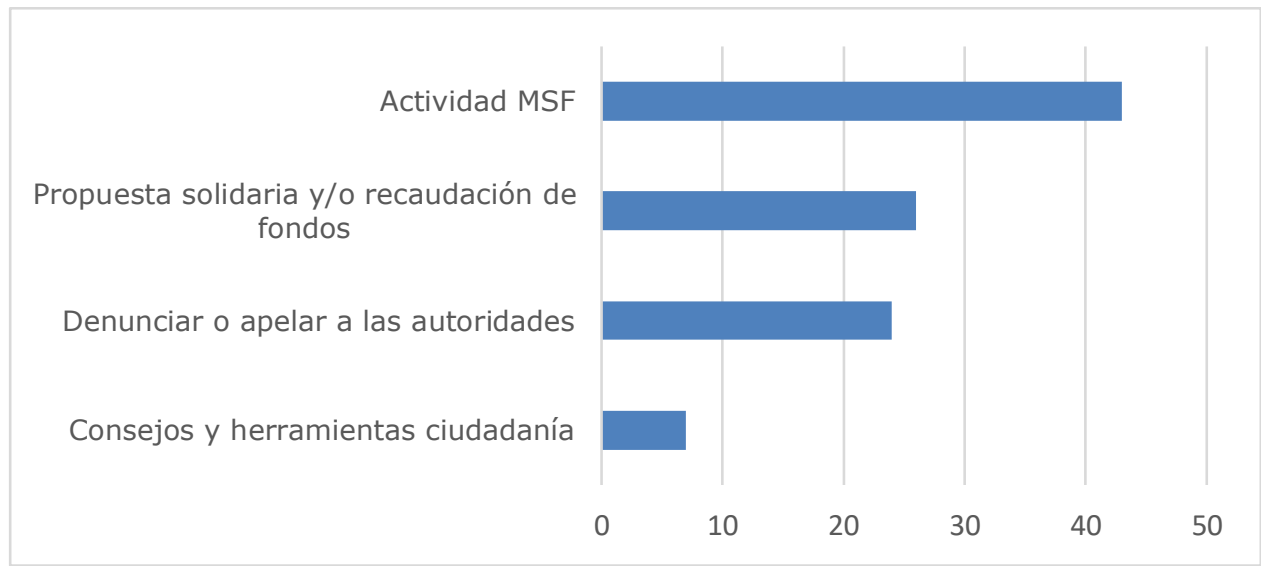

Fuente: elaboración propia. 
Figura 2. Resultados globales sobre la finalidad de los mensajes

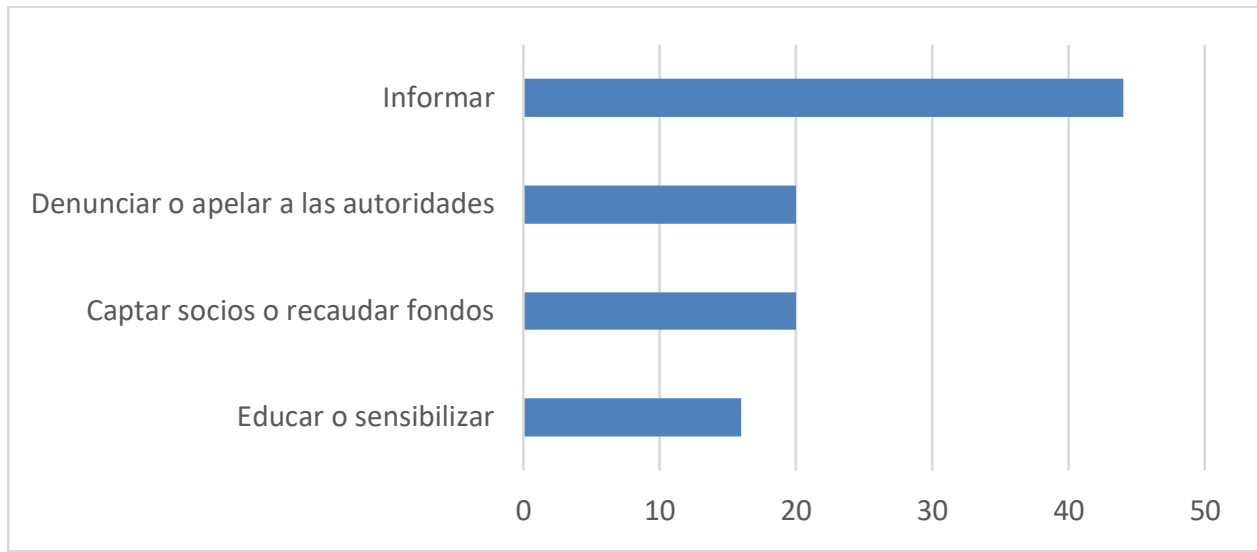

Fuente: elaboración propia.

Figura 3. Resultados globales sobre el enfoque racional o emotivo

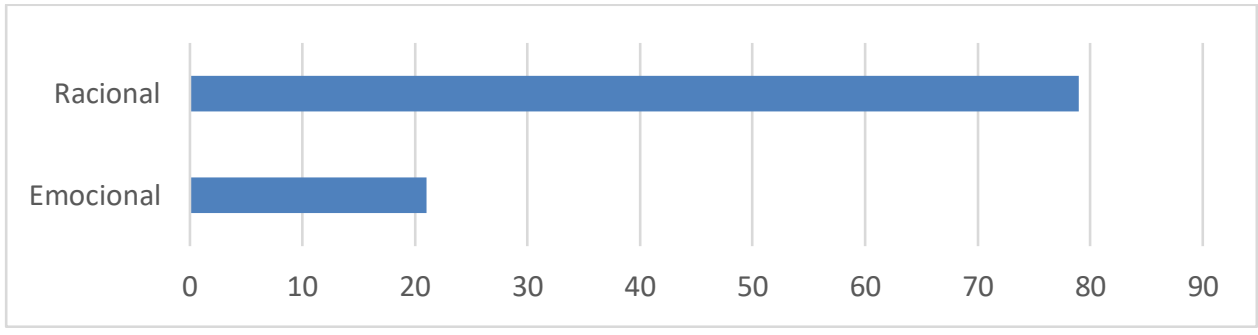

Fuente: elaboración propia.

Figura 4. Resultados globales sobre el emisor

Equipo global de MSF

Trabajador

Voluntario

Socio

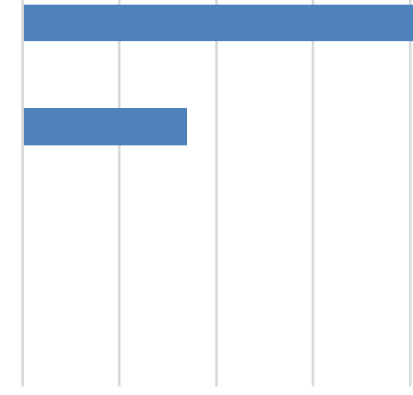

$0 \quad 10 \quad 20 \quad 30 \quad 40 \quad 50$

60

70

80

90

Fuente: elaboración propia. 
Figura 5. Resultados globales sobre el formato

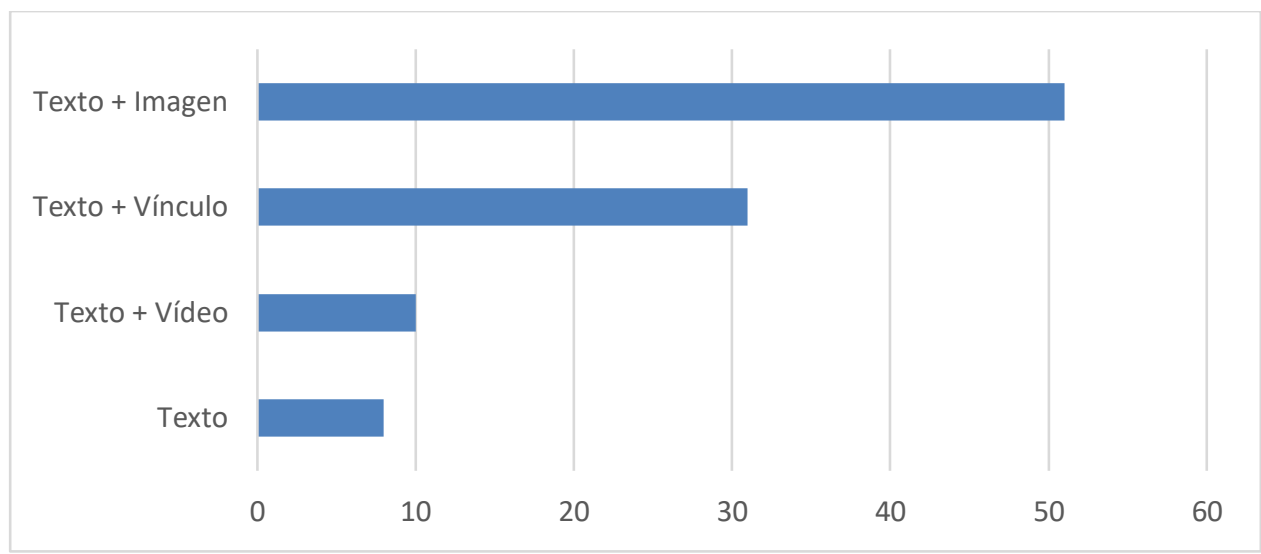

Fuente: elaboración propia.

\section{Conclusión y discusiones}

De los resultados del análisis podemos inferir algunas consideraciones generales sobre la comunicación llevada a cabo por MSF durante la crisis sanitaria en España.

En primer lugar, por la temática de los mensajes emitidos deducimos que el objetivo prioritario de la ONGD se ha centrado en explicar y describir su actuación durante la crisis. Se infiere de ello, en coherencia con una de las hipótesis planteadas, el especial interés de MSF por explicar su inédita actuación en España, que serviría también para dar a conocer de forma más directa al público español la forma en la que habitualmente actúa en otros países. Su actuación en España ha contribuido también como un ejercicio de rendición de cuentas y para reforzar sus atributos en términos de imagen corporativa respecto a su profesionalidad, experiencia y especialización como organización médico-humanitaria y especialmente en cuanto a las situaciones de crisis epidemiológica.

Otro de los ejes centrales de su comunicación ha sido la apelación y presión a las autoridades. Consideramos que la actuación de una ONGD en un país como España puede ser controvertida para sus socios o donantes, ya que supuestamente dedican sus recursos a apoyar a países empobrecidos. Actuar en España podría percibirse como una ruptura de ese compromiso e incluso enmarcar la solidaridad como sustitutiva de los deberes que debieran asumir las administraciones públicas. Creemos que, junto a la forma con la que MSF se ha presentado como entidad especializada en epidemias y la gravedad de la crisis de la COVID-19, que justificarían su inédita actuación en España, las acciones de presión política han servido a la ONGD para reforzar el marco de la 
justicia social frente al asistencialismo en un contexto como el español. Podríamos resumir su mensaje en que MSF ha decidido actuar en España porque se ha dado una situación muy excepcional provocada por una epidemia y esa es precisamente la especialidad de MSF, pero que en un país desarrollado corresponde a las autoridades la responsabilidad de prevenir y atender este tipo de situaciones. Aunque no ha sido objeto de análisis, destaca en este sentido el informe sobre las residencias de ancianos que tuvo una amplia repercusión en cuanto a sensibilizar sobre la situación de desamparo del colectivo y situar a MSF en el marco de la reivindicación en pro de la justicia social, subrayando la responsabilidad de las autoridades.

La recaudación de fondos, aunque ha estado siempre presente mediante mensajes específicos y también indirectamente en todas las acciones comunicativas de la ONGD, no parece haber sido una prioridad en este caso. Consideramos que MSF ha aprovechado la crisis para reforzar su imagen, ganar notoriedad y fidelizar a sus socios y donantes, lo que podría repercutir en un incremento de donaciones a largo plazo, pero sin ser este un objetivo inmediato.

Sí que sorprende de los resultados del análisis la escasez de mensajes educativos sobre prevención dirigidos al público general, lo que contradice parte de nuestra hipótesis inicial. Aunque una de sus principales líneas de actuación ha sido la formación sobre el virus y la enfermedad para responsables de la administración y profesionales sanitarios, por ejemplo, mediante guías especializadas o talleres, los consejos y herramientas sobre el virus dirigidos a la ciudadanía no han sido una prioridad para la ONGD. Quizás dadas las intensas campañas institucionales y la labor de los medios en este sentido (sobre higiene, detección de síntomas, etc.), MSF ha decidido centrarse en la formación específica a profesionales, que es su especialidad.

$\mathrm{Su}$ comunicación ha sido eminentemente informativa y descriptiva, básicamente mostrando su propia actuación durante la crisis. Aunque también ha hecho uso de discursos connotativos apelando emocionalmente a sus públicos, estos se han centrado en llamadas concretas de apoyo económico, en subrayar la gravedad de la situación o en aumentar la presión sobre las autoridades. El principal referente de los mensajes emitidos ha sido la propia organización y su acción médico-humanitaria. Más que centrarse en el problema, percibido claramente por la población española, o incluso en las soluciones al mismo, la ONGD parece haber centrado su comunicación en el producto que ofrece y en el que se concreta su solución propuesta ante este tipo de crisis, así como en la propia entidad como especialista en ofrecer dicho producto. Las temáticas, referentes, enfoques y formatos de la comunicación digital de MSF parecen coherentes con el fin señalado de explicar su actuación 
inédita en territorio español. No obstante, como se apuntaba en el marco teórico, la comunicación de la ONGD no aprovecha el potencial interactivo de las redes digitales, primando un uso instrumental de las mismas con mensajes de carácter informativo sobre la propia ONGD y su actuación más que una verdadera conversación con sus públicos, especialmente socios y donantes.

Concluimos pues que MSF ha enfocado su comunicación durante la crisis en lograr notoriedad y reforzar su imagen ante públicos potenciales o rendir cuentas ante sus actuales donantes y socios. Actuar en España le ha servido para mostrar al público local de forma más cercana lo que la ONGD hace habitualmente en sus intervenciones sobre el terreno. Su mensaje latente podríamos resumirlo de la siguiente forma: Este es el tipo de crisis sanitaria que a menudo azota a los países empobrecidos y que ahora podemos percibir en nuestro propio contexto; este es el tipo de crisis al que MSF está acostumbrada y en las que somos expertos; esta es la forma en la que actuamos con la máxima eficacia y profesionalidad y por lo que somos un referente en la atención médica y humanitaria.

\section{Agradecimientos}

A María Hernández, Yohannes Halefom y Tedros Gebremariam, cooperantes de MSF asesinados en Tigray (Etiopía) cuando trabajaban por un mundo mejor.

\section{Referencias bibliográficas}

ALDAMIZ, C. (2003). Marketing en ONGs de desarrollo: para su aplicación práctica. Madrid: FESIDE e IEPALA.

ALEIXANDRE, R.; CASTELLÓ, L. y VALDERRAMA, J. C. (2020). Información y comunicación durante los primeros meses de Covid-19. Infodemia, desinformación y papel de los profesionales de la información. Profesional de la información, 29(4), 1-17. doi.org/10.3145/epi.2020.jul.08

ALVARADO, M. (2003). La publicidad social, una modalidad emergente de comunicación (Tesis doctoral). Universidad Complutense de Madrid, Madrid.

ANDREASEN, A. R. (1994). Social marketing: Its definition and domain. Journal of Public Policy \& Marketing, 13(1), 108-114. doi.org/10.1177/074391569401300109

ANDRÉU, J. A. (2002). Las técnicas de análisis de contenido: una revisión actualizada. Sevilla: Fundación Centro de Estudios Andaluces.

ARBELÁEZ, M. y ONRUBIA, J. (2014). Análisis bibliométrico y de contenido. Dos metodologías complementarias para el análisis de la revista colombiana Educación y Cultura. Revista de Investigaciones UCM, 14(23), 14-31. doi.org/10.22383/ri.v14i1.5 
ARROYO, I. y MARTíN, R. (2011). La utilización de Internet en la comunicación expresiva de las ONG: Estudio exploratorio comparativo entre Argentina y España. Zer, 16(31), 243-263.

ARROYO, I.; BALADRóN, A. J. y MARTíN, R. (2013). La comunicación en redes sociales: percepciones y usos de las ONG españolas. Cuadernos.info, 32, 7788.

ARROYO, I. y BAÑOS, M. (2013). Tendencias de la comunicación del tercer sector en la web 2.0: Análisis retórico de los tropos. Icono 14, 11(2), 331-356. doi.org/10.7195/ri14.v11i2.556

ARROYO, I. y CALLE, S. (2018). Los community managers de las ONGD. Estudio de percepciones y usos de las redes sociales. Icono 14, 16(2), 121-142. doi.org/10.7195/ri14.v16i2.1189

BALAS, M. (2011). La gestión de la comunicación en el Tercer Sector. Madrid: ESIC. BARAYBAR, A. (2009). Conectando valores: Las nuevas estrategias de la comunicación online en el Tercer Sector. Icono 14, 7(2), 37-55. doi.org/10.7195/ri14.v7i2.316

BARDIN, L. (2002). El análisis de contenido. Madrid: Akal.

BENET, V. y Nos ALDÁs, E. (eds.) (2003). La publicidad en el tercer sector: tendencias y perspectivas de la comunicación solidaria. Barcelona: Icaria.

BERNABÉ, J. (2001). Las áreas de comunicación de las ONGD y el trabajo periodístico. Revista Española de Desarrollo y Cooperación, 7, 127-145.

CAMPBELL, D. \& LAMBRIGHT, K. (2019). Are You Out There? Internet Presence of Nonprofit Human Service Organizations. Nonprofit and Voluntary Sector Quarterly, 48(6), 1296-1311 doi.org/10.1177/0899764019852673

CÁRCAR, J. E. (2015). Las redes y los movimientos sociales ¿una acción colectiva o marketing viral? Icono 14, 13(1), 125-150.

doi.org/10.7195/ri14.v13i1.744

COULDRY, N. (2010). Why voice matters: Culture and politics after neoliberalism. London: Sage.

DE ANDRÉS, S. (2007). El nuevo papel de los públicos en el sistema publicitario. En M. I. MARTín y M. C. Alvarado (Eds.), Nuevas tendencias del siglo XXI (pp. 61-76). Sevilla: Comunicación Social.

DE BARTOLOMÉ, F.; JIMÉNEZ, C. y MORETó, L. (2020). La incertidumbre (científica) en tiempos del coronavirus. MSF Especial COVID-19 Contrarreloj, 118, 17. Recuperado de: https: //tinyurl.com/bxy894fm

DESCHAMPS, R. \& MCNUTT, K. (2014). Third sector and social media. Canadian Journal of Nonprofit and Social Economy Research, 5(2), 29-46.

ERRO, J. y VENTURA, J. (2002). El trabajo comunicativo de las ONGD en el País Vasco. Barcelona: Ariel. 
ESPARCIA, A.; KUnSCH, M. \& HASWANI, M. (2017). Prácticas comunicativas y perspectivas para el cambio social en las organizaciones no gubernamentales (ONGs), en España y Brasil. Organicom, 14(26), 147-166.

FERGUSON, D. P. (2017). Nongovernmental organization communication. In R.

L. HEATH \& W. JOHANSEN (Eds.), International encyclopedia of strategic communication (pp. 1-13). Hoboken, NJ: Wiley Blackwell.

García, M. C. y Del Hoyo, M. (2013). Redes sociales, un medio para la movilización juvenil. Zer, 18(34), 111-125.

GREENBERG, J. \& MACAULAY, M. (2009). NPO 2.0? Exploring the Web Presence of Environmental Nonprofit Organizations in Canada. Global Media Journal, 2(1), 63-88.

HAYES, N. \& WESTRUP, C. (2014). Consultants as intermediaries and mediators in the construction of information and communication technologies for development. Information Technologies and International Development, 10(2), 19-32.

HERRANZ, J. M. (2009). La transparencia y la rendición de cuentas en el tercer sector. Cuadernos de debate Fundación Luis Vives, 5, 78-81.

HERRANZ, J. M. (2010). La comunicación y la transparencia en las organizaciones no lucrativas. Madrid: Universidad Complutense de Madrid.

HILDEGART, L. (2006). La comunicación: Herramienta estratégica en la misión de las ONGD. FISEC-Estrategias, 5, 31-53.

KotLER, P. \& ZALTMAN, G. (1971). Social Marketing: An Approach to Planned Social Change. Journal of Marketing, 35(3), 3-12.

doi.org/10.2307/1249783

KRIPPENDORFF, K. (1990). Metodología de análisis de contenido. Teoría y práctica. Barcelona: Paidós.

LEMA, I.; RoDRíGUEZ, E. y BARRANQUERO, A. (2016). Jóvenes y tercer sector de medios en España: Formación en comunicación y cambios social. Comunicar, 24(48), 91-99 doi.org/10.3916/C48-2016-09

LOVEJOY, K. \& SAXTON, G. (2012). Information, community, and action: how nonprofit organizations use social media. Journal of Computer-Mediated Communication, 17(3), 337-353.

MARTín, R. (2007). La comunicación web de las ONGD. Signo y pensamiento, 26(51), 130-136.

MARTíneZ, J. L. (1998). La imagen de las ONG de desarrollo. Para ir dimensionando el tercer sector. Madrid: IEPALA.

MONTERO, M. J. (2003). El marketing de las ONGD. La gestión del cambio social. Madrid: Desclee. 
MonToliU, L. (2012). Las ONG en la red. Análisis de la presencia, la interactividad y la participación en Internet de las entidades del tercer sector catalán. AE-IC.MORIANO, J. (2019). La estrategia de comunicación en Twitter de las ONGD españolas. Recuperado de:

\section{https: / / tinyurl.com/2ypemzzw}

Nos ALDÁS, E. (2010). Lenguaje publicitario y discursos solidarios. Eficacia publicitaria, ¿eficacia cultural? Barcelona: Icaria.

ORSO, D.; FEDERICI, N.; CopetTI, R.; Vetrugno, L. \& TiZiAnA, B. (2020). Fake news in the COVID-19-era. European Journal of Emergency Medicine, 27(5), 327328. doi.org/10.1097/MEJ.0000000000000713

Pope, J. A.; SterRetT, E. \& ASAMOA, F. (2009). Developing a Marketing Strategy for Nonprofit Organizations: An Exploratory Study. Journal of Nonprofit \& Public Sector Marketing, 21(2), 184-201. doi.org/10.1080/10495140802529532

SEO, H.; KIM, J. Y. \& YANG, S. (2009). Global activism and new media: A study of transnational NGOs' online public relations. Public Relations Review, 35(2), 123-126.

SorIA, M. (2011). La interacción de los públicos en las ONG 2.0: El estado actual de la comunicación social. Revista internacional de relaciones públicas, 1(2), 175-195. doi.org/10.5783/RIRP-2-2011-10-175-195

SorIA, M. (2015). El mensaje informativo en Facebook y Twitter en las ONGD: un enfoque desde sus públicos. Ámbitos, 27, 1-20.

Tian, F.; LABBAN, A.; SHEARER, R. \& GAI, Q. (2019). The Impact of Social Media Activity on Nonprofit Donations in China. Voluntas, 32(2), 1-10. doi.org/10.1007/s11266-019-00168-7

URIBE, F.; RIALP, J. y J LLONCH, J. (2013). El uso de las redes sociales digitales como herramienta de marketing en el desempeño empresarial. Cuadernos de Administración, 26(47), 205-231.

VAN-DiJK, T. (2017). Análisis Crítico del Discurso. Revista Austral de Ciencias Sociales, 30, 203-222. doi.org/10.4206/rev.austral.cienc.soc. 2016.n30-10

VERNIS, A. y MENDILUCE, J. (1998). La gestión de las organizaciones no lucrativas. Bilbao: Deusto.

VIDAL, P. (Dir.) (2003). Llibre Blanc del Tercer Sector Cívico-social a Catalunya. Barcelona: EADOP. 